\title{
Comparison of Direct Bilirubin on Two Automated Systems: Influence of Delta Bilirubin
}

\section{Ekta Bansal}

\section{ABSTRACT}

Introduction: In a routine clinical laboratory having more than one automated system, comparison of methods experiment provides a means to assess any method's performance. It helps to estimate systematic (constant and proportional) difference between two methods. If the difference between two methods is small and clinically acceptable, then these two methods can be used interchangeably. In this study, we have compared direct bilirubin on two automated systems and tried to analyze the cause behind the difference between the two.

Materials and methods: Serum samples obtained from normal individuals as well as those with unconjugated and conjugated hyperbilirubinemia were analyzed on Cobas 6000 and Olympus AU 2700 simultaneously.

Results: There was a significant difference in the values of direct bilirubin in patients with conjugated hyperbilirubinemia on the two automated systems. No difference was seen in normal persons and in patients with unconjugated hyperbilirubinemia.

Conclusion: Delta bilirubin might be a contributing factor to the difference between direct bilirubin on the two systems, as it is expected only in patients with conjugated hyperbilirubinemia.

Keywords: Comparison of methods, Conjugated hyperbilirubinemia, Direct bilirubin, Unconjugated hyperbilirubinemia.

How to cite this article: Bansal E. Comparison of Direct Bilirubin on Two Automated Systems: Influence of Delta Bilirubin. Indian J Med Biochem 2018;22(1):75-77.

\section{Source of support: Nil}

Conflict of interest: None

\section{INTRODUCTION}

Fractionation of serum bilirubins is invaluable in the diagnosis and treatment of hepatic disorders, hemolysis, and neonatal jaundice. The chemical nature of direct and indirect bilirubin fractions was elucidated by Billing et al. ${ }^{1}$ They isolated three bilirubin fractions, unconjugated bilirubin (indirect reacting), bilirubin monoglucuronide and

\section{Associate Professor}

Department of Biochemistry, Dayanand Medical College \& Hospital, Ludhiana, Punjab, India

Corresponding Author: Ekta Bansal, Associate Professor Department of Biochemistry, Dayanand Medical College \& Hospital, Ludhiana, Punjab, India, Phone: +919914578002 e-mail: dr_ekta_bansal@dmch.edu diglucuronide that is conjugated bilirubin (direct reacting). Kuenzle et $\mathrm{al}^{2}$ were the first to obtain four bilirubin fractions: unconjugated bilirubin (alpha-bilirubin), monoconjugated bilirubin (beta-bilirubin), diconjugated bilirubin (gamma-bilirubin), and a fraction strongly bound to protein (delta-bilirubin). They used an open column chromatography technique that did not involve deproteinization step. Only high-performance liquid chromatography (HPLC) methods allow for relatively rapid separation and quantification of all the four bilirubin fractions. Most routine automated methods for bilirubin analysis utilize diazo method modifications to fractionate bilirubin into total and direct reacting fractions, also known as direct bilirubin. Most of these routine methods are incapable of differentiating delta bilirubin from other direct reacting bilirubin fractions. Delta bilirubin is the serum bilirubin fraction composed of bilirubin conjugates that are tightly and covalently bound to serum proteins. It has a half life in serum of 12 to 14 days, approximating to that of albumin, the predominant serum protein. ${ }^{3}$

In this study, we processed serum samples on two different automated systems and compared the results of direct bilirubin measured by them and tried to find out if there is any influence of delta bilirubin on the results.

\section{MATERIALS AND METHODS}

Samples received in the clinical biochemistry laboratory for liver function tests were analyzed on Cobas 6000 and categorized into normal and patients with conjugated and unconjugated hyperbilirubinemia. Out of these 10 serum samples from healthy individuals, 10 samples from patients with unconjugated hyperbilirubinemia, and 40 samples from patients with conjugated hyperbilirubinemia were then analyzed on Olympus AU 2700 autoanalyzer. All the estimations were done on the day of collection.

Instrument maintenance, calibration, and operation were performed according to the manufacturer's recommendations. Cobas 6000 uses the diazo method in which conjugated bilirubin and $\delta$-bilirubin (direct bilirubin) react directly with diazotized sulfanilic acid in acid buffer to form the red-colored azobilirubin. ${ }^{4}$ In AU 2700, a stabilized diazonium salt, 3,5-dichlorophenyl diazonium tetrafluoroborate couples directly with direct (conjugated) bilirubin in an acid medium to form azobilirubin. ${ }^{5}$ 
The personnel assaying the samples were experienced in the methodology used. For Cobas 6000 system, the within-run coefficient of variation $(\mathrm{CV})$ for direct bilirubin was $0.4 \%$ at $6.96 \mathrm{mg} / \mathrm{dL}$ and $0.2 \%$ at $12.5 \mathrm{mg} / \mathrm{dL}$, and the total CVs were $1.0 \%$ at $4.63 \mathrm{mg} / \mathrm{dL}$ and $0.4 \%$ at $16.2 \mathrm{mg} /$ dL. Within-run CVs for Olympus 2700 were $1.78 \%$ at 1.0 $\mathrm{mg} / \mathrm{dL}$ and $1.16 \%$ at $6.78 \mathrm{mg} / \mathrm{dL}$. The total CV was $2.92 \%$ at $1.0 \mathrm{mg} / \mathrm{dL}$ and $2.2 \%$ at $6.78 \mathrm{mg} / \mathrm{dL}$.

The results obtained from the two analyzers were subjected to regression and correlation analysis and the $\mathrm{p}$-value was calculated by applying the t-test.

\section{RESULTS}

In normal individuals, the level of mean direct bilirubin on Cobas 6000 was found to be $0.24 \mathrm{mg} / \mathrm{dL}$, while that on AU 2700 was $0.23 \mathrm{mg} / \mathrm{dL}$. In patients with unconjugated hyperbilirubinemia, the level of direct bilirubin came out to be nearly equal in both the autoanalyzers, i.e., $0.72 \mathrm{mg} /$ $\mathrm{dL}$ on Cobas 6000 and $0.75 \mathrm{mg} / \mathrm{dL}$ on AU 2700. But on comparing patients with conjugated hyperbilirubinemia, the mean level of direct bilirubin on Cobas was found to be higher at $8.32 \mathrm{mg} / \mathrm{dL}$, while on AU 2700, it was $5.6 \mathrm{mg} / \mathrm{dL}$ with a significant p-value of 0.039 (Table 1). The difference between the two was seen at all values of direct bilirubin ranging between 0.5 and $25 \mathrm{mg} / \mathrm{dL}$. When the direct bilirubin estimated on Cobas 6000 at various ranges was compared, it was seen that the mean value of direct bilirubin of corresponding patients measured on AU 2700 was on a lower side. As the value of direct bilirubin measured on Cobas increased, the difference between the two systems increased proportionately (Table 2).

Table 1: Comparison of direct bilirubin on Cobas 6000 and Olympus AU 2700

\begin{tabular}{|c|c|c|c|c|c|}
\hline \multirow[b]{2}{*}{ Group } & \multicolumn{2}{|c|}{ Cobas } & \multicolumn{2}{|c|}{ Olympus } & \multirow[b]{2}{*}{$p$-value } \\
\hline & $\begin{array}{l}\text { Mean } \\
(m g \%)\end{array}$ & $S D$ & $\begin{array}{l}\text { Mean } \\
(m g \%)\end{array}$ & $S D$ & \\
\hline $\begin{array}{l}\text { Conjugated } \\
\text { hyperbilirubinemia }\end{array}$ & 8.32 & 5.65 & 5.60 & 3.93 & 0.039 \\
\hline Normal persons & 0.24 & 0.15 & 0.23 & 0.26 & 0.731 \\
\hline $\begin{array}{l}\text { Unconjugated } \\
\text { hyperbilirubinemia }\end{array}$ & 0.72 & 0.18 & 0.75 & 0.11 & 0.439 \\
\hline
\end{tabular}

Table 2: Mean level of direct bilirubin at different ranges on Cobas and Olympus

\begin{tabular}{llll}
\hline $\begin{array}{l}\text { Direct } \\
\text { bilirubin } \\
\text { range } \\
(m g \%)\end{array}$ & $\begin{array}{l}\text { Mean level of direct } \\
\text { bilirubin measured } \\
\text { on Cobas 6000 } \\
(m g \%)\end{array}$ & $\begin{array}{l}\text { Mean level of } \\
\text { direct bilirubin } \\
\text { on Olympus }\end{array}$ & \\
\hline $0-4$ & 1.98 & 2700 (mg\%) & Difference \\
$>4-<8$ & 6.03 & 1.36 & 0.62 \\
$>8-<12$ & 10.2 & 3.90 & 2.13 \\
$>12-<16$ & 12.6 & 7.20 & 3.0 \\
$>16-<20$ & 18.1 & 8.46 & 4.14 \\
$>20$ & 25.2 & 11.81 & 6.29 \\
\hline
\end{tabular}

Table 3: Regression and correlation results between two systems by taking $Y=$ direct bilirubin in Cobas

\begin{tabular}{lll}
\hline Factor & $B$ & $p$-value \\
\hline Constant & 0.53 & 0.201 \\
Direct bilirubin in Olympus 2700 & 1.39 & 0.000 \\
r-value & 0.966 & 0.000 \\
\hline
\end{tabular}

Direct bilirubin in Cobas $=0.53+1.39$ (direct bilirubin in Olym)

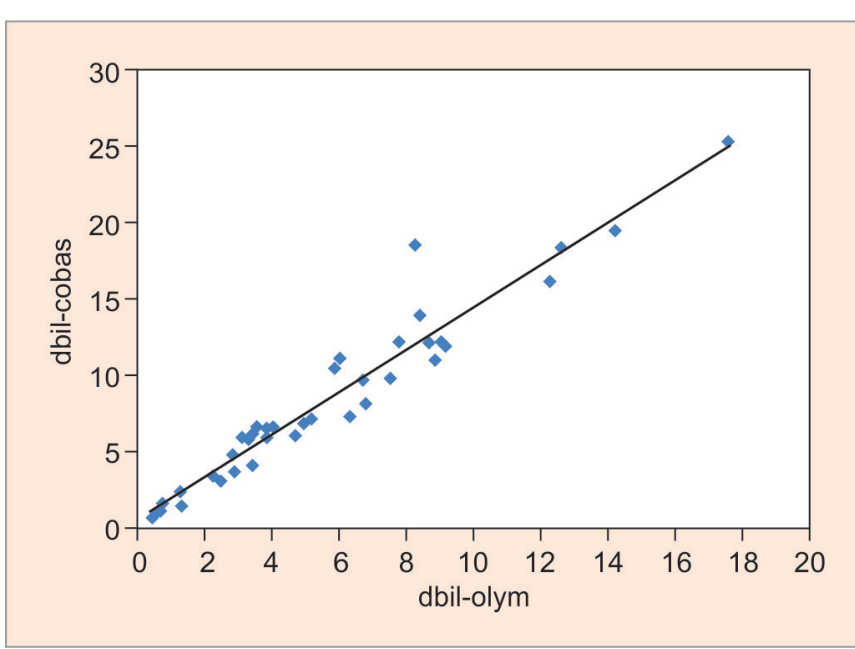

Graph 1: Relationship between direct bilirubin on Cobas and Olympus $(r=0.996)$

Regression and correlation analysis showed a constant of 0.53 and an r-value of 0.966 (Table 3 and Graph 1).

\section{DISCUSSION}

The method and instrument validation is an important issue in clinical laboratory work. Each new method should be validated when introduced in routine laboratory work. ${ }^{6,7} \mathrm{~A}$ simple experiment that could be performed to assess performance is by the comparison of methods. ${ }^{8}$ This experiment compares results obtained using one method with those obtained using the other. The aim of this experiment is to estimate the systematic difference between the two methods, e.g., to find out if there is a significant difference in their relative accuracy using real patient samples. ${ }^{8}$ In this comparison study, we saw that there was a constant difference between the direct bilirubin values obtained on the Cobas c system and those obtained on Olympus 2700. This difference was not statistically significant in samples from healthy individuals, as well as those with unconjugated hyperbilirubinemia. In both these categories, the direct bilirubin level was within normal limits. However, in patients with conjugated hyperbilirubinemia, direct bilirubin estimated by Cobas was significantly higher than that obtained from Olympus. The difference between the two results was seen at all the ranges and it increased with an increase in the level of direct bilirubin. Delta bilirubin could be one of the factors behind this difference since it 
is expected only in the serum of patients with conjugated hyperbilirubinemia ${ }^{3,9}$ Delta bilirubin fraction accounts for a considerable amount of total bilirubin in the serum of patients with conjugated hyperbilirubinemia The percentage of total bilirubin accounted for by the delta bilirubin fraction might differ considerably, depending on the particular time in the course of illness that serum samples were obtained. ${ }^{3}$ Ostrea et $\mathrm{al}^{10}{ }^{10}$ in a study on 40 infants with jaundice of various etiologies, reported that delta bilirubin, a tightly protein bound bilirubin, was observed in significant amounts in infants with elevated direct bilirubin. Its concentration, which ranged from 10 to $73 \%$ of the total bilirubin, was related to the duration rather than to the cause of the jaundice. No discriminating value in diagnosis could be attributed to the delta bilirubin measurement. This may reflect differences in the formation and clearance of delta bilirubin compared with bilirubin monoconjugates and diconjugates. Ye et al, ${ }^{11}$ in their study on infants with biliary atresia, found increased delta bilirubin levels with increasing levels of conjugated bilirubin and a longer duration of cholestasis. They concluded that understanding the relation among delta bilirubin, conjugated bilirubin, and direct-reacting bilirubin levels can help in the interpretation of the clinical extent of cholestasis in infants and children with biliary atresia, assisting in the diagnosis and management of these infants.

Delta bilirubin estimation, while not absolutely essential for patient management, can provide useful information regarding the time course of an illness. ${ }^{12}$ Some studies have shown that an increase in the percentage of serum delta bilirubin indicates the effectiveness of biliary drainage in man. An analysis of serum delta bilirubin for 7 days can distinguish good drainage patients from poor drainage patients. ${ }^{13}$

Our study shows that the results of direct bilirubin on the two systems differ and delta bilirubin could be behind this, which can be confirmed by HPLC. This is a limitation of this study since HPLC was not done. In view of the significant difference in direct bilirubin values in patients with conjugated hyperbilirubinemia on the two analyzers, the results cannot be used interchangeably.
This has to be explained to the treating clinicians. This dilemma particularly concerns those laboratories which have more than one analyzer. In our set-up, we have tried to overcome this situation by emphasizing on the clinicians to get the serial samples of the patient tested on the same analyzer.

\section{REFERENCES}

1. Billing BH, Cole PG, Lathe GH. The excretion of bilirubin as a glucuronide giving the direct van der Bergh reaction. Biochemical J 1957 Apr;65(4):774-783.

2. Kuenzle CC, Maier C, Ruttner JR. The nature of four bilirubin fractions from serum and of three bilirubin fractions from bile. J Lab Clin Med 1966 Feb;67(2):294-306.

3. Weiss JS, Gautam A, Lauff JJ, Sundberg MW, Jatlow P, Boyer JL, Seligson D. The clinical importance of a protein-bound fraction of serum bilirubin in patients with hyperbilirubinemia. N Engl J Med 1983 Jul;309(3):147-150.

4. Malloy HT, Evelyn KA. The determination of bilirubin with the photoelectric colorimeter. J Biol Chem 1937 Aug;119:481-490.

5. Van den Bergh AA, Mueller P. Ueber eine direkte and indirekte diazoreaktion auf bilirubin. Biochem Z 1916;77:90-103.

6. Gasljevic V. Method validation and measurement uncertainty. Biochem Med 2010 Feb;20(1):57-63.

7. Imre S, Vlase L, Muntean DL. Bioanalytical method validation. Rev Rom Med Lab 2008 Mar;10(1):13-21.

8. Westgard, JO. The comparison of methods experiment. Madison (WI): Westgard QC; 2010. [cited 2010 Dec 27]. Available from: http:/ / www.westgard.com/lesson23.htm\#10.

9. Lauff JJ, Kasper ME, Wu TW, Ambrose RT. Isolation and preliminary characterization of a fraction of bilirubin in serum that is firmly bound to protein. Clin Chem $1982 \mathrm{Apr} ; 28(4 \mathrm{Pt} 1)$ : 629-637.

10. Ostrea EM Jr, Ongtengco EA, Tolia VA, Apostol E. The occurrence and significance of the bilirubin species, including delta bilirubin, in jaundiced infants. J Pediatr Gastroenterol Nutr 1988 Jul-Aug;7(4):511-516.

11. Ye W, Rosenthal P, Magee JC, Whitington PF; Childhood Liver Disease Research and Education Network. Factors determining $\delta$-Bilirubin levels in infants with biliary atresia. J Pediatr Gastroenterol Nutr 2015 May;60(5):659-663.

12. Rosenthal $\mathrm{P}$, Jennings MT. Serum delta bilirubin estimation by an automated method. Eur J Clin Chem Clin Biochem 1992 Jan;30(1):39-41.

13. Kozaki N, Shimizu S, Higashijima H, Kuroki S, Yamashita $H$, Yamaguchi K, Chijiiwa K, Tanaka M. Significance of serum delta bilirubin in patients with obstructive jaundice. J Surg Res 1998 Sep;79(1):61-65. 